\title{
PENGELOLAHAN JURNAL ELEKTRONIK DENGAN ONLINE JURNAL SYSTEM
}

\author{
Untung Rahardja ${ }^{1}$ \\ Augury El Rayeb ${ }^{2}$ \\ Heriyanto ${ }^{3}$ \\ e-mail : untung.rahardja@faculty.raharja.ac.id,auguryelrayeb@faculty.raharja.ac.id, \\ heriyanto@ti.raharja.ac.id,
}

Diterima :8 Juli 2010/Disetujui : 13 Agustus 2010

\begin{abstract}
Achieving education system as a social institution is strong and authoritative to empower all levels of society developed into a quality human and thus able to proactively address challenges of times that are always changing. In line with the vision of National Education, the Government seems to have increasingly realized that to achieve the vision, the one thing that must be realized is a knowledge-based society (knowledge-based society). To make it happen, the utilization of science and technology as the prime mover (prime mover) are continually being pursued through studies that are done as well as placeholders to facilitate such research. Program college is one institution that engages in computer science have implemented a system with the use of information technology into a system or container all the results of research and studies. However, currently the shelter system research results that there is still manual, not using a structured database and need to involve relevant personnel to control the flow and use of many paper systems for supportability data file, so that the system is certainly not running optimally. Of the problems it is necessary to an Online Journal of Systems that can run directly on (self-service), can also communicate viaemail (intranet), use a little paper (paper less), and also have been using a database of good because it can give effect quite significantly to the continuity of 4 (four) pillar IT Elearning is the result of environmental research in Higher Education Program. It can be concluded that the concept of Online Journal system. It can be a solution to the latest in spurring scientific community improvement and progress in the field of Computer Science and Information Technology (IT).
\end{abstract}

1. Dosen Jurusan Sistem Informasi, STMIK Raharja

Jl. jend Sudirman No. 40 Modern Cikokol-Tangerang Telp. 5529692

2. Dosen Jurusan Sistem Komputer, STMIK Raharja

Jl. jend Sudirman No. 40 Modern Cikokol-Tangerang Telp. 5529692

3. Mahasiswa Jurusan Teknik Informatika, STMIK Raharja

J1. jend Sudirman No. 40 Modern Cikokol-Tangerang Telp. 5529692 


\section{ABSTRAKSI}

Terwujudnya sistem Pendidikan sebagai pranata sosial yang kuat dan berwibawa untuk memberdayakan semua lapisan masyarakat berkembang menjadi manusia yang berkualitas sehingga mampu dan proaktif menjawab tantangan zaman yang selalu berubah. Sejalan dengan Visi Pendidikan Nasional tersebut, Pemerintah rupanya telah makin menyadari bahwa untuk mewujudkan visi tersebut, satu hal yang mesti diwujudkan adalah masyarakat berbasis pengetahuan (knowledge based society). Untuk mewujudkannya, pemanfaatan iptek sebagai penggerak utama (prime mover) terus diupayakan melalui penelitianpenelitian yang di lakukan serta memfasilitasi sebagai penampung hasil penelitian tersebut. Perguruan tinggi Raharja yang merupakan Salah satu lembaga pendidikan yang bergerak di bidang ilmu computer telah menerapkan system dengan pemanfaatan teknologi informasi menjadi sebuah system atau wadah penampung semua hasil-hasil riset dan penelitianpenelitian. Namun, Saat ini Sistem penampungan hasil-hasil riset yang ada masih bersifat manual, belum menggunakan database terstruktur dan perlu melibatkan personil terkait untuk mengendalikan alur sistem serta penggunaan banyak kertas untuk berkas data dukungnya, Sehingga system tersebut tentunya tidak berjalan secara maksimal. Dari permasalahan tersebut maka perlu adanya sebuah Online Jurnal Sistem yang dapat di jalankan secara langsung (self service), dapat pula berkomunikasi via-email (intranet),penggunaan sedikit kertas (paper less), serta sudah menggunakan database yang baik karena dapat memberikan dampak yang cukup signifikan terhadap kelangsungan 4 (empat) pilar IT E-learning hasil dari penelitian di lingkungan Perguruan Tinggi Raharja. Dapat disimpulkan bahwa dengan konsep Online Jurnal Sistem ini dapat menjadi sebuah solusi terkini dalam memacu peningkatan kualitas masyarakat ilmiah dan kemajuan di bidang Ilmu Komputer dan Informasi Teknologi (IT).

Kata kunci : online jurnal system

\section{PENDAHULUAN}

Perkembangan IT (Information Technology) memacu suatu cara baru dalam kehidupan, dan kehidupan dimulai sampai dengan akhir, kehidupan seperti ini dikenal dengan e-life, artinya kahidupan ini sudah dipengaruhi oleh berbagai kebutuhan secara elektronik. Berdasarkan pada pengetahuan (knowledge), seiring dengan perkembangannya, Perguruan Tinggi Raharja merupakan perguruan tinggi yang bergerak di bidang ilmu komputer yang berada di Propinsi Banten dan terletak hanya 10 (sepuluh) menit dari Bandara Internasional Soekarno-Hatta. Banyak penghargaan yang telah di raih dari hasil penelitian-penelitian yang sudah di hasilkan, salah satunya adalah memenangkan WSA 2009 - Indonesia E-Learning and Education Category of Intranet Product Raharja Multimedia Edutainment $(R M E)$. Pada saat ini Perguruan Tinggi Raharja pun telah meningkatkan mutu dan kualitasnya melalui sertifikat akreditasi dari Badan Akreditasi Nasional Perguruan Tinggi (BAN-PT) diantaranya menyatakan bahwa program studi Diploma Tiga 
Komputerisasi Akuntansi di AMIK Raharja Informatika terakreditasi A. Selain itu, Perguruan Tinggi Raharja telah masuk peringkat 100 universitas teratas dan perguruan tinggi terbaik di Republik Indonesia, serta diperolehnya sertifikasi ISO 9001:2008 dengan nomor sertifikat: JKT 6007007 sebagai pengakuan mutu pengelolaan manajemen Perguruan Tinggi.

Perguruan Tinggi Raharja mempunyai 4 (empat) pilar IT E-learning yang di hasilkan dari hasil penelitian-penelitian yang terdiri dari SIS (Student Information Services)[1], RME (Raharja Multimedia Edutainment)[2], INTEGRAM (Integrated Raharja Marketing)[3], dan GO (Green Orchestra)[4] adalah instrumen Perguruan Tinggi Raharja sebagai kampus unggulan sesuai dengan visinya yaitu menuju perguruan tinggi unggulan yang selalu berinovasi, menghasilkan lulusan yang berkompeten di bidang sistem informasi, teknik informatika dan sistem komputer serta memiliki daya saing yang tinggi dalam era globalisasi.



Gambar 1.4 (empat) Pilar IT E-Learning Perguruan Tinggi Raharja

Gambar diatas menjelaskan bahwa 4 (empat) Pilar IT E-learning tersebut berjalan harmonis membentuk bangunan yang kokoh pada institusi Perguruan Tinggi Raharja yang secara berkesinambungan melakukan perbaikan (countinues improvment), berbagi sumber daya (resource sharing) dari dan oleh Pribadi Raharja serta saling terintegrasi (integration) satu sama lain.

Namun, dari hasil penelitian-penelitian yang sudah banyak di hasilkan apakah di lingkungan Perguruan Tinggi Raharja sudah mempunyai sistem pendokumentasian 
yang efektif dan efisien untuk menyimpan data-data penting dari setiap penelitian yang di hasilkan?

\section{PERMASALAHAN}

Melihat pada sistem-sistem serta kegiatan operasional yang diterapkan pada Perguruan Tinggi Raharja sebagian besar sudah berjalan secara terkomputerisasi, salah satu aspek yang bersentuhan dengan aktivitas pendukung di dalam lingkungan akademik adalah adanya unsur karya atau penelitian-penelitian secara ilmiah yang di hasilkan oleh kalangan akademisi ( para dosen pengajar dan unsur mahasiswa) yang di olah menjadi sebuah karya tulis (jurnal ilmiah) dan di dokumentasikan pada sebuah web jurnal CCIT yang ada di Perguruan Tinggi Raharja. Namun dari sistem yang sudah di terapkan pada web jurnal yang ada pada Perguruan Tinggi Raharja, yang saat ini masih menggunakan cara manualisasi di dalam pelaksanaannya, sehingga akan membuat pekerjaan tidak efektif dan efisien. Pada era teknologi yang saat ini telah berkembang pesat, segala bentuk informasi sangatlah dibutuhkan dengan cepat, akurat serta bentuk penyajiannya dapat di kemas dalam berbagai media, salah satunya adalah teknologi berbasis Web. maka diperlukannya suatu proses administratif jurnal secara on line dan otomatis yang dilakukan secara mandiri (self service). Menyadari bahwa perkembangan zaman dan untuk memenuhi kebutuhan masyarakat akan teknologi, perguruan tinggi di tuntut untuk selalu berinovasi dan membentuk manusia yang mempunyai produktivitas agar selalu melahirkan ide-ide yang berkualitas, untuk itu maka diperlukan juga sebuah sistem yang di bangun secara terstruktur dan keamanan data terjamin kualitasnya agar jika sewaktu-waktu di perlukan data-data yang menyangkut penelitian tersebut dapat dengan mudah di peroleh. namun dari sistem yang sudah di terapkan pada web jurnal yang ada pada Perguruan Tinggi Raharja, yang saat ini masih menggunakan cara manualisasi di dalam pelaksanaannya, sehingga akan membuat pekerjaan tidak efektif dan efisien. Pada era teknologi yang saat ini telah berkembang pesat, segala bentuk informasi sangatlah dibutuhkan dengan cepat, akurat serta bentuk penyajiannya dapat di kemas dalam bentuk digital, salah satunya adalah teknologi berbasis Web. maka diperlukannya suatu proses administratif jurnal secara on line dan otomatis yang dilakukan oleh sistem

\section{LITERATURE REVIEW}

Banyak penelitian yang sebelumnya dilakukan berkenaan dengan Literature Review mengenai konsep OJS (Online Journal System) dan AEMS (Auto Electronic Mail System). Dalam upaya pengembangan keamanan sistem database 
server ini perlu dilakukan studi pustaka sebagai salah satu dari penerapan metode penelitian yang akan dilakukan. Diantaranya adalah mengidentifikasikan kesenjangan (identify gaps), menghindari pembuatan ulang (reinventing the wheel), mengidentifikasikan metode yang pernah dilakukan, meneruskan penelitian sebelumnya, serta mengetahui orang lain yang spesialisasi dan area penelitiannya sama dibidang ini. Beberapa literature review tersebut adalah sebagai berikut:

1. Jaringan Internasional untuk Ketersediaan Publikasi Ilmiah (INASP) untuk mengembangkan portal penelitian ilmiah di Afrika ${ }^{[6]}$, Jaringan Internasional untuk Ketersediaan Publikasi Ilmiah (INASP) adalah sebuah organisasi amal yang didirikan tahun 1992 oleh Dewan Internasional untuk Science (ICSU), dan didaftarkan sebagai lembaga amal Inggris pada tahun 2004.

Melalui kemitraan strategis, partisipasi stakeholder dan komitmen untuk tanggung jawab sosial, INASP. Program-program ini saat ini berfokus pada penguatan komunikasi penelitian, dengan penekanan khusus pada kebutuhan negara berkembang dan negara berkembang

2. Nepal ${ }^{[8]}$, (NepJOL) dimulai pada bulan Juni 2006 dan resmi diluncurkan pada bulan September 2007. Ini adalah proyek yang didukung oleh Jaringan Internasional untuk Ketersediaan Publikasi Ilmiah (INASP). Ini bertujuan untuk mempromosikan kesadaran dan penggunaan Nepal-jurnal diterbitkan dalam semua disiplin dengan menyediakan akses ke isi tabel (TOCs), abstrak dan teks lengkap di Internet.

3. Proceedings ITB, jurnal ilmiah resmi ITB, telah diterbitkan sejak 1961. Jurnal ini merupakan sarana publikasi hasil penelitian dalam bidang IPTEKS yang dilakukan oleh civitas akademika ITB dan oleh kontributor dari luar ITB. Sejak edisi 2007 [ Volume 39], Proceedings ITB mengubah namanya menjadi ITB Journal dan mengeluarkan 4 seri, yaitu,

4. ITB Journal of Science terbit dua kali setahun pada bulan Maret dan September. Naskah ditulis dalam bahasa Inggris. ISSN:1978-3043.

5. ITB Journal of Engineering Science terbit dua kali setahun pada bulan Mei dan November. Naskah ditulis dalam bahasa Inggris. ISSN: 1978-3051.

6. ITB Journal of Information and Communication Technology terbit dua kali setahun pada bulan Mei dan November. Naskah ditulis dalam bahasa Inggris. ISSN: 1978-3086.

7. ITB Journal of Visual Art and Design terbit tiga kali setahun pada bulan Maret, Agustus dan Desember. Naskah ditulis dalam bahasa Indonesia. ISSN: 19783078. Mulai Volume 35 No. 1, 2003, abstrak dan artikel ITB Journal yang telah diterbitkan dapat dibaca secara online dengan mengunjungi situs web 
Lembaga Penelitian dan Pengabdian kepada Masyarakat, Institut Teknologi Bandung, pada http://www.lppm.itb.ac.id. Seluruh terbitan ITB Journal diindex oleh Google Scholar. ITB Journal of Science dan ITB Journal of Engineering Science terakreditasi DIKTI dan diindex oleh Scopus. ITB Journal diterbitkan oleh Lembaga Penelitian dan Pengabdian kepada Masyarakat, Institut Teknologi Bandung. Untuk informasi lebih lanjut, silahkan hubungi kami melalui email proceedings@1ppm.itb.ac.id.Download Informasi untuk Penulis and Template ITB Journal.

8. OJS, as well as the Erudit publishing system ${ }^{[9]}$, Sistem untuk Penerbitan Jurnal Elektronik (SIER) adalah hasil dari peramalan teknologi yang dilakukan oleh IBICT untuk mengidentifikasi aplikasi yang akan memungkinkan pengolahan dan penyebaran produksi ilmiah Brasil di Web Sistem SIER muncul, dan pada tahun 2003 dari penyesuaian Open Journal System (OJS), perangkat lunak manajemen dan penerbitan jurnal elektronik yang dikembangkan oleh Public Knowledge Project (PKP), University of British Columbia. Ini adalah inisiatif IBICT inovatif yang segera setelah terjemahan dari bahasa Portugis ke dalam perangkat lunak OJS, web menerbitkan berkala pertama yang menggunakan teknologi ini, jurnal Ilmu Informasi. Sejak itu, IBICT memulai proses dan distribusi SIER penerbit Brasil tertarik penerbitan jurnal ilmiah dapat diakses secara bebas di web dan mempromosikan pelatihan teknis dalam penggunaan alat ini dalam pelatihan sistematis yang dilakukan dari November 2004 di berbagai daerah dengan negara hanya lima tahun keberadaannya, SIER itu mengakibatkan penciptaan lebih dari 1.000 jurnal ilmiah Web di Brasil.

9. http://www.jurnal.lipi.go.id/ Terhitung sejak 1 Januari 2004, situs ini dikelola secara resmi oleh LIPI sebagai pengembangan sarana sejenis yang telah dikembangkan dengan berhasil oleh komunitas fisika Indonesia di fisik@net. Dengan pengembangan ini, sarana ini bisa dimanfaatkan secara lebih optimal oleh seluruh komunitas ilmiah di Indonesia dan manca negara. Sarana ini memanfaatkan infrastruktur yang disediakan oleh LIPI untuk repositori data ilmiah lokal dan global di ARSIP LIPI

10. http://lib.ugm.ac.id Unit Pelaksana Teknis (UPT) Perpustakaan Universitas Gadjah Mada didirikan pada tanggal 1 Maret 1951. Perpustakaan UGM pada mulanya menempati gedung di jalan Setjodiningratan (sekarang jalan Sultan Agung). Pada tahun 1959, pindah ke jalan C.Simanjuntak, menempati gedung bekas Konferensi Rencana Colombo(Gedung Panca Dharma, Sekip Unit V), dan sekarang menjadi gedung UPT Perpustakaan Unit II. Tanggal 31 Juli 1975 UGM membangun gedung perpustakaan di Bulaksumur sebelah 
Selatan Gedung Kantor Pusat yang diresmikan oleh Menteri Dalam Negeri (Bapak Amir Machmud), dan sekarang menjadi gedung UPT Perpustakaan Unit I. Gedung Unit I pada awalnya digunakan untuk mahasiswa tingkat sarjana muda, sedangkan gedung Unit II bagi mahasiswa tingkat sarjana. Namun setelah dihapuskannya tingkat sarjana muda di perguruan tinggi, peraturan tersebut tidak berlaku lagi.

Dari sepuluh Literature Review yang ada, telah banyak penelitian mengenai pengembangan sistem untuk untuk penerbitan jurnal elektronik. Untuk penelitian terkait keamanan belum banyak dilakukan oleh para peneliti diatas. Namun demikian dapat disimpulkan pula secara keseluruhan bahwa belum banyak peneliti yang secara khusus membahas sistem penerbitan jurnal elektronik yang berada di lokal area (intranet).

\section{PEMECAHAN MASALAH}

Salah satu aspek yang bersentuhan dengan aktivitas pendukung di dalam lingkungan akademik adalah adanya unsur karya atau penelitian-penelitian secara ilmiah yang di hasilkan oleh kalangan akademisi ( para dosen pengajar dan unsur mahasiswa) yang di olah menjadi sebuah karya tulis (jurnal ilmiah) dan di dokumentasikan pada sebuah sistem administrative dan pendokumentasian untuk sebuah penelitian. Untuk mengatasi masalah diatas, dibutuhkan sebuah sistem yang dapat di jalankan secara online. OJS open source merupakan solusi untuk mengelola dan penerbitan ilmiah jurnal secara online dan sudah menggunakan AMS (atumatic mail system). OJS sangat fleksibel dioperasikan karena OJS dapat di gabungkan ke dalam server yang sudah ada ataupun dapat di buat di komputer lokal dengan mengkondisikan komputer tersebut sebagai server secara mandiri, editor jurnal manajemen dan sistem penerbitan yang telah dirancang untuk membuat waktu dan energi untuk para pengurus jurnal menjadi lebih efisien, tugas-tugas administratif yang berhubungan dengan mengedit jurnal dapat di lakukan secara online tanpa harus di cetak sehingga bisa meminimalisir penggunaan kertas, efisiensi proses editorial dan mengurangi dampak pemanasan global. sistem ini berusaha untuk meningkatkan kualitas masyarakat ilmiah dan penerbitan jurnal melalui sejumlah inovasi, salah satu aspek yang bersentuhan dengan aktivitas pendukung di dalam lingkungan akademik adalah adanya unsur karya atau penelitian-penelitian secara ilmiah yang di hasilkan oleh kalangan akademisi ( para dosen pengajar dan unsur mahasiswa) yang diolah 
menjadi sebuah karya tulis (jurnal ilmiah) dan di dokumentasikan pada sebuah web jurnal CCIT yang ada di Perguruan Tinggi Raharja.

\section{IMPLEMENTASI}

Untuk dapat masuk ke dalam tampilan menu utama program perancangan online jurnal sistem, terlebih dahulu harus melakukan login dengan tampilan sebagai berikut:

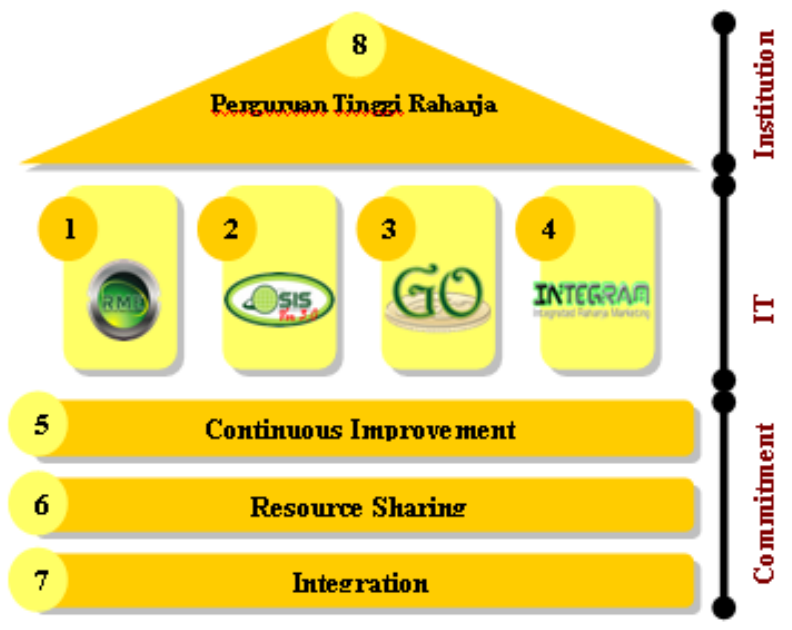

Gambar 1.4 (empat) Pilar IT E-Learning Perguruan Tinggi Raharja

Gambar diatas menjelaskan bahwa 4 (empat) Pilar IT E-learning tersebut berjalan harmonis membentuk bangunan yang kokoh pada institusi Perguruan Tinggi Raharja yang secara berkesinambungan melakukan perbaikan (countinues improvment), berbagi sumber daya (resource sharing) dari dan oleh Pribadi Raharja serta saling terintegrasi (integration) satu sama lain.

Namun, dari hasil penelitian-penelitian yang sudah banyak dihasilkan apakah di lingkungan Perguruan Tinggi Raharja sudah mempunyai sistem pendokumentasian yang efektif dan efisien untuk menyimpan data-data penting dari setiap penelitian yang dihasilkan?

\section{PERMASALAHAN}

Melihat pada sistem-sistem serta kegiatan operasional yang diterapkan pada Perguruan Tinggi Raharja sebagian besar sudah berjalan secara terkomputerisasi, 
salah satu aspek yang bersentuhan dengan aktivitas pendukung di dalam lingkungan akademik adalah adanya unsur karya atau penelitian-penelitian secara ilmiah yang dihasilkan oleh kalangan akademisi ( para dosen pengajar dan unsur mahasiswa) yang diolah menjadi sebuah karya tulis (jurnal ilmiah) dan didokumentasikan pada sebuah web jurnal CCIT yang ada di Perguruan Tinggi Raharja. Namun dari sistem yang sudah di terapkan pada web jurnal yang ada pada Perguruan Tinggi Raharja, yang saat ini masih menggunakan cara manualisasi di dalam pelaksanaannya, sehingga akan membuat pekerjaan tidak efektif dan efisien. Pada era teknologi yang saat ini telah berkembang pesat, segala bentuk informasi sangatlah dibutuhkan dengan cepat, akurat serta bentuk penyajiannya dapat dikemas dalam berbagai media, salah satunya adalah teknologi berbasis Web. maka diperlukannya suatu proses administratif jurnal secara on line dan otomatis yang dilakukan secara mandiri (self service). Menyadari bahwa perkembangan zaman dan untuk memenuhi kebutuhan masyarakat akan teknologi, perguruan tinggi di tuntut untuk selalu berinovasi dan membentuk manusia yang mempunyai produktivitas agar selalu melahirkan ide-ide yang berkualitas, untuk itu maka diperlukan juga sebuah sistem yang di bangun secara terstruktur dan keamanan data terjamin kualitasnya agar jika sewaktu-waktu di perlukan data-data yang menyangkut penelitian tersebut dapat dengan mudah diperoleh. Namun dari sistem yang sudah di terapkan pada web jurnal yang ada pada Perguruan Tinggi Raharja, yang saat ini masih menggunakan cara manualisasi di dalam pelaksanaannya, sehingga akan membuat pekerjaan tidak efektif dan efisien. Pada era teknologi yang saat ini telah berkembang pesat, segala bentuk informasi sangatlah dibutuhkan dengan cepat, akurat serta bentuk penyajiannya dapat dikemas dalam bentuk digital, salah satunya adalah teknologi berbasis Web. maka diperlukannya suatu proses administratif jurnal secara on line dan otomatis yang dilakukan oleh sistem

\section{LITERATURE REVIEW}

Banyak penelitian yang sebelumnya dilakukan berkenaan dengan Literature Review mengenai konsep OJS (Online Journal System) dan AEMS (Auto Electronic Mail System). Dalam upaya pengembangan keamanan sistem database server ini perlu dilakukan studi pustaka sebagai salah satu dari penerapan metode penelitian yang akan dilakukan. Diantaranya adalah mengidentifikasikan kesenjangan (identify gaps), menghindari pembuatan ulang (reinventing the wheel), mengidentifikasikan metode yang pernah dilakukan, meneruskan penelitian sebelumnya, serta mengetahui orang lain yang spesialisasi dan area penelitiannya sama dibidang ini. Beberapa literature review tersebut adalah sebagai berikut: 
1. Jaringan Internasional untuk Ketersediaan Publikasi Ilmiah (INASP) untuk mengembangkan portal penelitian ilmiah di Afrika ${ }^{[6]}$, Jaringan Internasional untuk Ketersediaan Publikasi Ilmiah (INASP) adalah sebuah organisasi amal yang didirikan tahun 1992 oleh Dewan Internasional untuk Science (ICSU), dan didaftarkan sebagai lembaga amal Inggris pada tahun 2004.

Melalui kemitraan strategis, partisipasi stakeholder dan komitmen untuk tanggung jawab sosial, INASP. Program-program ini saat ini berfokus pada penguatan komunikasi penelitian, dengan penekanan khusus pada kebutuhan negara berkembang dan negara berkembang

2. Nepal ${ }^{[8]}$, (NepJOL) dimulai pada bulan Juni 2006 dan resmi diluncurkan pada bulan September 2007. Ini adalah proyek yang didukung oleh Jaringan Internasional untuk Ketersediaan Publikasi Ilmiah(INASP). Ini bertujuan untuk mempromosikan kesadaran dan penggunaan Nepal-jurnal diterbitkan dalam semua disiplin dengan menyediakan akses ke isi tabel (TOCs), abstrak dan teks lengkap di Internet.

3. Proceedings ITB, jurnal ilmiah resmi ITB, telah diterbitkan sejak 1961. Jurnal ini merupakan sarana publikasi hasil penelitian dalam bidang IPTEKS yang dilakukan oleh civitas akademika ITB dan oleh kontributor dari luar ITB. Sejak edisi 2007 [ Volume 39], Proceedings ITB mengubah namanya menjadi ITB Journal dan mengeluarkan 4 seri, yaitu,

4. ITB Journal of Science terbit dua kali setahun pada bulan Maret dan September. Naskah ditulis dalam bahasa Inggris. ISSN:1978-3043.

5. ITB Journal of Engineering Science terbit dua kali setahun pada bulan Mei dan November. Naskah ditulis dalam bahasa Inggris. ISSN: 1978-3051.

6. ITB Journal of Information and Communication Technology terbit dua kali setahun pada bulan Mei dan November. Naskah ditulis dalam bahasa Inggris. ISSN: 1978-3086.

7. ITB Journal of Visual Art and Design terbit tiga kali setahun pada bulan Maret, Agustus dan Desember. Naskah ditulis dalam bahasa Indonesia. ISSN: 19783078. Mulai Volume 35 No. 1, 2003, abstrak dan artikel ITB Journal yang telah diterbitkan dapat dibaca secara online dengan mengunjungi situs web Lembaga Penelitian dan Pengabdian kepada Masyarakat, Institut Teknologi Bandung, pada http://www.lppm.itb.ac.id. Seluruh terbitan ITB Journal diindex oleh Google Scholar. ITB Journal of Science dan ITB Journal of Engineering Science terakreditasi DIKTI dan diindex oleh Scopus. ITB Journal diterbitkan oleh Lembaga Penelitian dan Pengabdian kepada Masyarakat, Institut Teknologi Bandung. Untuk informasi lebih lanjut, silahkan hubungi kami melalui 
email proceedings@1ppm.itb.ac.id.Download Informasi untuk Penulis and Template ITB Journal.

8. OJS, as well as the Erudit publishing system ${ }^{[9]}$, Sistem untuk Penerbitan Jurnal Elektronik (SIER) adalah hasil dari peramalan teknologi yang dilakukan oleh IBICT untuk mengidentifikasi aplikasi yang akan memungkinkan pengolahan dan penyebaran produksi ilmiah Brasil di Web Sistem SIER muncul, dan pada tahun 2003 dari penyesuaian Open Journal System (OJS), perangkat lunak manajemen dan penerbitan jurnal elektronik yang dikembangkan oleh Public Knowledge Project (PKP), University of British Columbia. Ini adalah inisiatif IBICT inovatif yang segera setelah terjemahan dari bahasa Portugis ke dalam perangkat lunak OJS, web menerbitkan berkala pertama yang menggunakan teknologi ini, jurnal Ilmu Informasi. Sejak itu, IBICT memulai proses dan distribusi SIER penerbit Brasil tertarik penerbitan jurnal ilmiah dapat diakses secara bebas di web dan mempromosikan pelatihan teknis dalam penggunaan alat ini dalam pelatihan sistematis yang dilakukan dari November 2004 di berbagai daerah dengan negara hanya lima tahun keberadaannya, SIER itu mengakibatkan penciptaan lebih dari 1.000 jurnal ilmiah Web di Brasil.

9. http://www.jurnal.lipi.go.id/Terhitung sejak 1 Januari 2004, situs ini dikelola secara resmi oleh LIPI sebagai pengembangan sarana sejenis yang telah dikembangkan dengan berhasil oleh komunitas fisika Indonesia di fisik@net. Dengan pengembangan ini, sarana ini bisa dimanfaatkan secara lebih optimal oleh seluruh komunitas ilmiah di Indonesia dan manca negara. Sarana ini memanfaatkan infrastruktur yang disediakan oleh LIPI untuk repositori data ilmiah lokal dan global di ARSIP LIPI

10. http://lib.ugm.ac.id Unit Pelaksana Teknis (UPT) Perpustakaan Universitas Gadjah Mada didirikan pada tanggal 1 Maret 1951. Perpustakaan UGM pada mulanya menempati gedung di jalan Setjodiningratan (sekarang jalan Sultan Agung). Pada tahun 1959, pindah ke jalan C.Simanjuntak, menempati gedung bekas Konferensi Rencana Colombo (Gedung Panca Dharma, Sekip Unit V), dan sekarang menjadi gedung UPT Perpustakaan Unit II. Tanggal 31 Juli 1975 UGM membangun gedung perpustakaan di Bulaksumur sebelah Selatan Gedung Kantor Pusat yang diresmikan oleh Menteri Dalam Negeri (Bapak Amir Machmud), dan sekarang menjadi gedung UPT Perpustakaan Unit I. Gedung Unit I pada awalnya digunakan untuk mahasiswa tingkat sarjana muda, sedangkan gedung Unit II bagi mahasiswa tingkat sarjana. Namun setelah dihapuskannya tingkat sarjana muda di perguruan tinggi, peraturan tersebut tidak berlaku lagi. 
Dari sepuluh Literature Review yang ada, telah banyak penelitian mengenai pengembangan sistem untuk untuk penerbitan jurnal elektronik. Untuk penelitian terkait keamanan belum banyak dilakukan oleh para peneliti diatas. Namun demikian dapat disimpulkan pula secara keseluruhan bahwa belum banyak peneliti yang secara khusus membahas sistem penerbitan jurnal elektronik yang berada di lokal area (intranet).

\section{PEMECAHAN MASALAH}

Salah satu aspek yang bersentuhan dengan aktivitas pendukung di dalam lingkungan akademik adalah adanya unsur karya atau penelitian-penelitian secara ilmiah yang dihasilkan oleh kalangan akademisi ( para dosen pengajar dan unsur mahasiswa) yang diolah menjadi sebuah karya tulis (jurnal ilmiah) dan di dokumentasikan pada sebuah sistem administrative dan pendokumentasian untuk sebuah penelitian. Untuk mengatasi masalah diatas, dibutuhkan sebuah sistem yang dapat di jalankan secara online. OJS open source merupakan solusi untuk mengelola dan penerbitan ilmiah jurnal secara online dan sudah menggunakan AMS (atumatic mail system). OJS sangat fleksibel dioperasikan karena OJS dapat di gabungkan ke dalam server yang sudah ada ataupun dapat di buat di komputer lokal dengan mengkondisikan komputer tersebut sebagai server secara mandiri, editor jurnal manajemen dan sistem penerbitan yang telah dirancang untuk membuat waktu dan energi untuk para pengurus jurnal menjadi lebih efisien, tugas-tugas administratif yang berhubungan dengan mengedit jurnal dapat di lakukan secara online tanpa harus di cetak sehingga bisa meminimalisir penggunaan kertas, efisiensi proses editorial dan mengurangi dampak pemanasan global. sistem ini berusaha untuk meningkatkan kualitas masyarakat ilmiah dan penerbitan jurnal melalui sejumlah inovasi, salah satu aspek yang bersentuhan dengan aktivitas pendukung di dalam lingkungan akademik adalah adanya unsur karya atau penelitian-penelitian secara ilmiah yang di hasilkan oleh kalangan akademisi ( para dosen pengajar dan unsur mahasiswa) yang diolah menjadi sebuah karya tulis (jurnal ilmiah) dan di dokumentasikan pada sebuah web jurnal CCIT yang ada di Perguruan Tinggi Raharja.

\section{IMPLEMENTASI}

Untuk dapat masuk ke dalam tampilan menu utama program perancangan online jurnal sistem, terlebih dahulu harus melakukan login dengan tampilan sebagai berikut: 


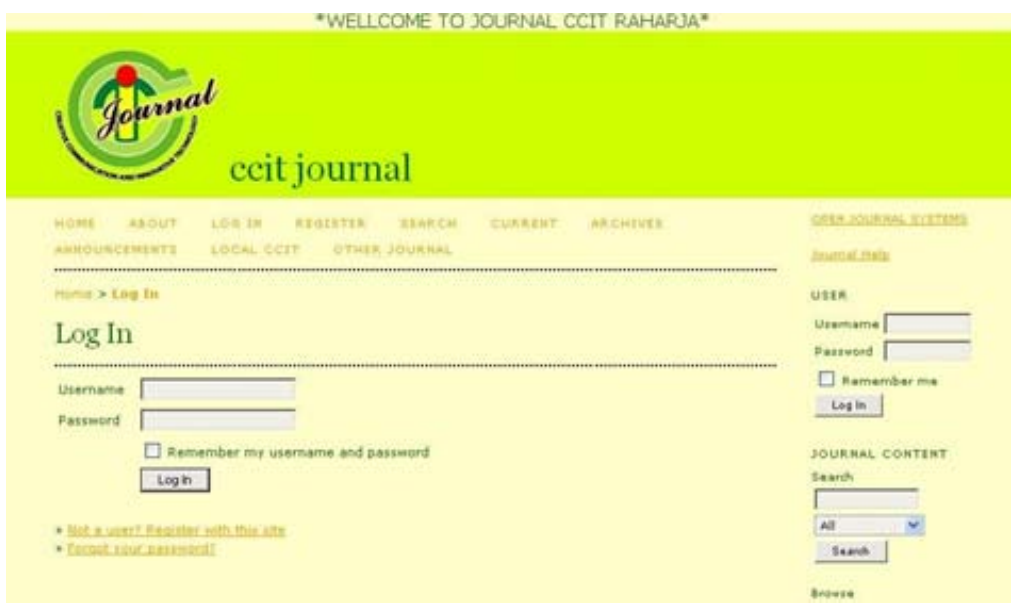

Gambar 2. halaman depan jurnal CCIT

Untuk dapat berkomunikasi melalui email jaringan yang ada di dalam lingkungan perguruan tinggi raharja (intranet) maka di perlukan setting pada file SMTPMailer.inc yang berfungsi sebagai jalur penghubung antara pesan yang di kirimkan otomatis oleh mesin mail yang sudah di program ke jaringan mail server yang sudah terkoneksi ke seluruh personal yang ada di lingkungan perguruan tinggi raharja berdasarkan filterisasi account yang sudah di buat pada saat pendaftaran di Jurnal CCIT sebagai member.

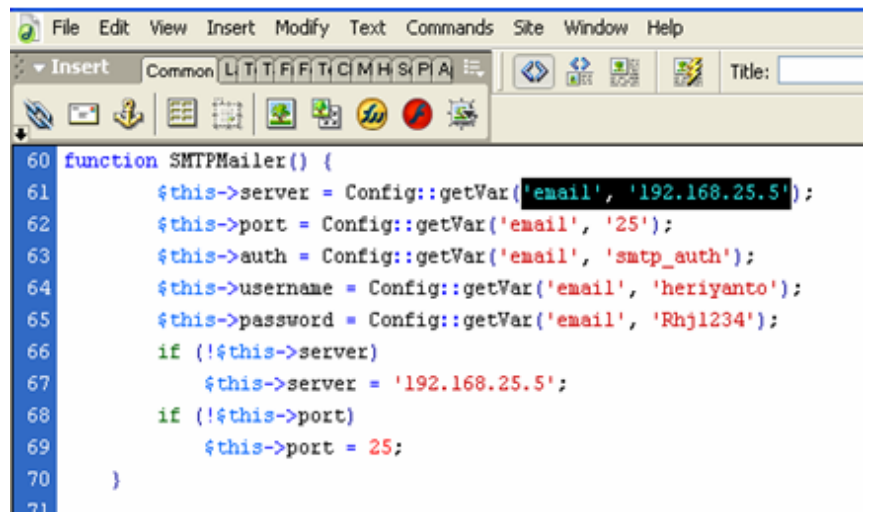

Gambar 3. (file config.inc.php).

Kemudian settingan konfigurasi system untuk penyesuaian IP address yang ada di server mail yang di aktif di sesuaikan kan kedalam konfigurasi sistem yang ada di 
Jurnal CCIT (file config.inc.php). agar mail system dapat berfungsi dengan baik.


\section{KESIMPULAN}

Gambar 4. Halaman Konfigurasi System

Berdasarkan dari hasil analisa yang telah dilakukan maka perancangan Online jurnal sistem ini memang sangat diperlukan guna meningkatkan mutu kualitas Perguruan Tinggi Raharja serta membentuk seluruh sistem informasi yang terdapat di dalamnya agar berjalan secara terkomputerisasi. Sistem ini merupakan suatu sistem berbasis web yang dapat mempermudah pihak pengurus dalam hal berkomunikasi dan pengelolaan jurnal, mengurangi pemakaian banyak kertas untuk pencetakan dokumen serta dijalankan secara online sehingga mudah di akses di seluruh lingkungan Perguruan Tinggi Raharja.

\section{DAFTAR PUSTAKA}

1. Untung Rahardja, Laporan Penelitian Student Information Services (SIS) Pada Perguruan Tingi Raharja, Tangerang: Raharja Enrichment Centre, Perguruan Tinggi Raharja, 2007.

2. Untung Rahardja, Laporan Penelitian Raharja Multimedia Edutainment (RME) Pada Perguruan Tingi Raharja, Tangerang: Raharja Enrichment Centre, Perguruan Tinggi Raharja, 2007.

3. Lilik Agustin, Desain dan Implementasi INTEGRAMpada Perguruan Tinggi Raharja, Tangerang: STMIK Raharja, 2005. 
4. Untung Rahardja, Laporan Penelitian Green Orchestra (GO) Pada Perguruan Tingi Raharja, Tangerang: Raharja Enrichment Centre, Perguruan Tinggi Raharja, 2008.

5. Jaringan Internasional untuk Ketersediaan Publikasi Ilmiah (INASP) untuk mengembangkan portal penelitian ilmiah di Afrika ${ }^{[6]}$

6. Nepal ${ }^{[8]}$, (NepJOL) dimulai pada bulan Juni 2006 dan resmi diluncurkan pada bulan September 2007.

7. da Fonseca, R.M.S. (2004, June). Open Journal Systems. Paper presented at the ICCC 8th International Conference on Electronic Publishing, as well as the Erudit publishing system ${ }^{[9]}$, Sistem untuk Penerbitan Jurnal Elektronik (SIER), Brasilia.

8. Muthayan, S. (2003). Open access research and the public domain in South African universities: The Public Knowledge Project's Open Journal Systems. Paper presented at the International Symposium on Open Access and the Public Domain in Digital Data and Information for Science, UNESCO, Paris.

9. Suber, P. (2006, July 04). "Timeline of the open access movement". http:// www.earlham.edu/ p peters/fos/timeline.htm. Retrieved 2006-11-28.

10. Willinsky, J. (2005). Open Journal Systems: An example of open source software for journal management and publishing. Library Hi-Tech 23 (4), 504-519.

11. ITB Journal of Science terbit dua kali setahun pada bulan Maret dan September. Naskah ditulis dalam bahasa Inggris. ISSN:1978-3043. di akses pada tanggal 16 may 2010

12. ITB Journal of Engineering Science terbit dua kali setahun pada bulan Mei dan November. Naskah ditulis dalam bahasa Inggris. ISSN: 1978-3051. di akses pada tanggal 16 may 2010

13. ITB Journal of Information and Communication Technology terbit dua kali setahun pada bulan Mei dan November. Naskah ditulis dalam bahasa Inggris. ISSN: 1978-3086. di akses pada tanggal 16 may 2010

14. ITB Journal of Visual Art and Design terbit tiga kali setahun pada bulan Maret, Agustus dan Desember. Naskah ditulis dalam bahasa Indonesia. ISSN: 19783078. di akses pada tanggal 16 may 2010

15. Institut Teknologi Bandung, pada http://www.lppm.itb.ac.id. di akses pada tanggal 16 may 2010

16. ITB Journal of Science dan ITB Journal of Engineering Science terakreditasi

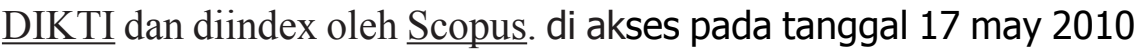

